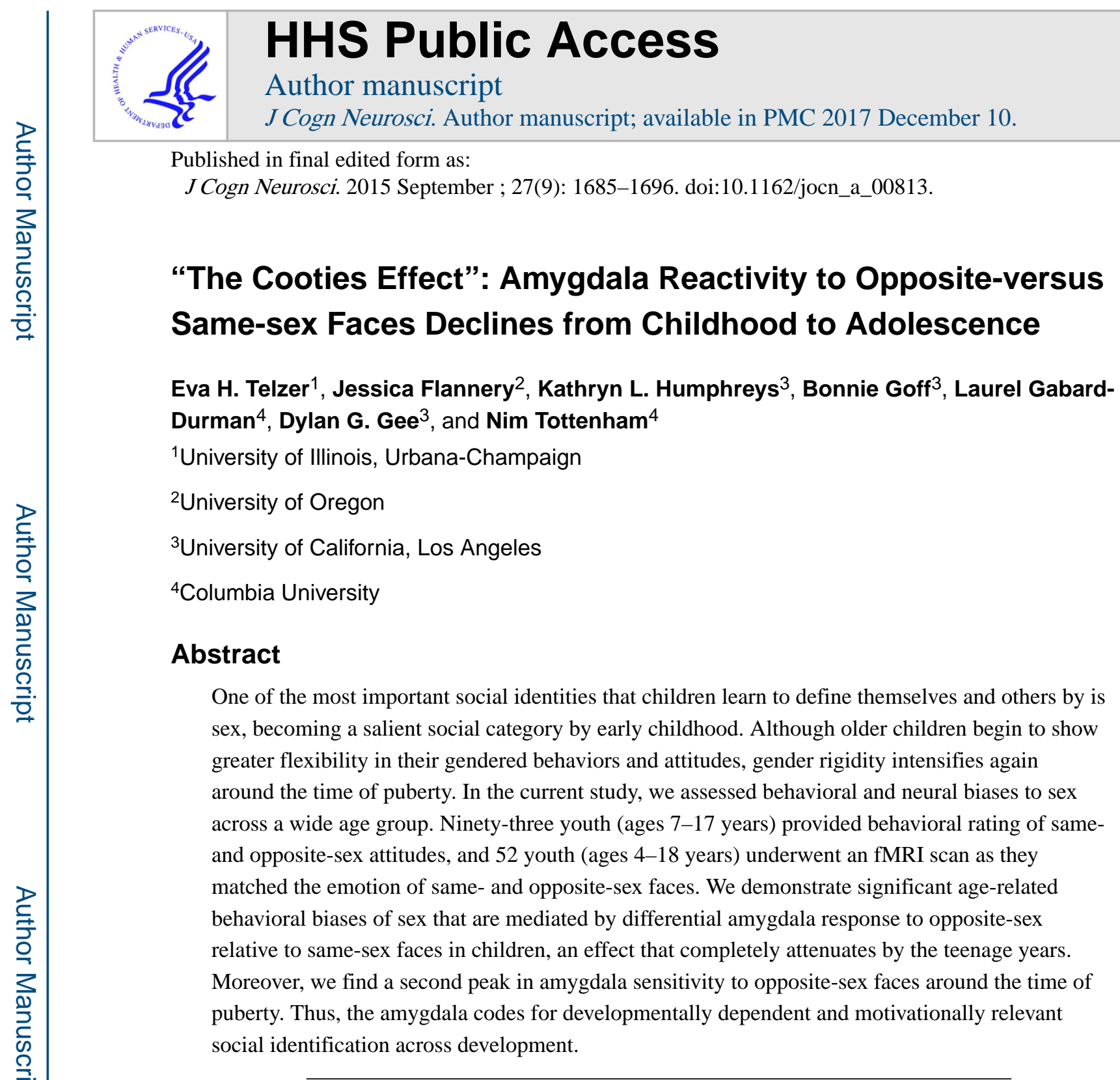

\title{
INTRODUCTION
}

One of the most important social identities that children learn to define themselves and others by is sex, becoming a salient social category by early childhood (Martin \& Ruble, 2010; Aydt \& Corsaro, 2003). Decades of research across cultures and species demonstrate the ubiquity of sex-segregated patterns of social interaction and behavior among children. Both human and primate youth exhibit preferences to play with same-sex peers and tend to hold attitudes favoring their sex ingroup over outgroup (Mahajan et al., 2011; Alexander \& Hines, 2002; Powlishta, 1995; Serbin, Moller, Gulko, Powlishta, \& Colburne, 1994; Martin, Wood, \& Little, 1990; La Freniere, Strayer, \& Gauthier, 1984).

Reprint requests should be sent to Eva H. Telzer, Department of Psychology, University of Illinois, 603 E. Daniel St, Champaign, IL 61820, or via ehtelzer@illinois.edu. 


\section{Development of Sex Biases}

Early Childhood-According to Developmental Intergroup Theory (Bigler \& Liben, 2007), the external world (parents, teachers, etc.) socializes children to focus on sex differences from an early age. Children then tend to categorize their social worlds based on gender, often developing strong gender stereotypes that become rigid (Powlishta, 2004). Sex stereotyping begins to emerge between 2 and 4 years (Serbin, Powlishta, \& Gulko, 1993; Trautner, 1992). By ages 3 to 4 years, children report liking their own sex more than the other, think that their peers will also like their own sex better, and ascribe more positive characteristics to their own sex (Halim, Ruble, \& Tamis-LeMonda, 2013; Yee \& Brown, 1994). Furthermore, children tend to exaggerate similarities among their own sex and differences between the sexes (see Powlishta, 2004). Moreover, children exhibit a strong preference to play in same-sex groups, such that by age 6 years, the ratio of same-sex to opposite-sex play partners increases to 11:1 (Serbin et al., 1993; Maccoby \& Jacklin, 1987).

With increased sex stereotyping in childhood comes the belief that one's own sex is better, and the opposite-sex has cooties and should be avoided (Powlishta, 2004). Young boys and girls are often wary of one another with children exaggerating male-female differences even when none exist, reaffirming the boundaries and asymmetries between girls and boys, a concept referred to as gender boundary maintenance (Martin \& Ruble, 2004; Aydt \& Corsaro, 2003; Sroufe, Bennett, Englund, Urban, \& Shulman, 1993). For example, boys and girls often use "sexual scripts" to define strict gender boundaries, including teasing (e.g., being accused of liking the opposite sex) and heterosexual rituals (e.g., cross-sex chasing; Leaper, 1994). During these interactions, girls and boys often behave as if the other sex could contaminate them, a well-known childhood phenomenon called "cooties" (Leaper, 1994; Samuelson, 1980). The concept of cooties represents the salience of otherness ascribed to the opposite sex.

Middle Childhood-Although early childhood represents a developmental stage during which sex differences are highly salient and the most rigid, this tends to wane by middle childhood when boys and girls show greater flexibility in their gendered behaviors and attitudes (Trautner et al., 2005; Martin \& Ruble, 2004; Serbin et al., 1993; Signorella, Bigler, $\&$ Liben, 1993). For instance, rigid sex-stereotyping reaches a peak at around 6 years and then decreases with age (Trautner, 1992), and biases favoring same-sex relative to oppositesex peers declines in elementary school (e.g., Egan \& Perry, 2001). As children get older, they begin to understand that boys and girls have many similarities with each other and that there is substantial variability within each sex category. This greater flexibility may render sex a less salient social category by late childhood.

Adolescence-Gender rigidity tends to intensify again during adolescence. Pubertal development is thought to revive youths' concern with gender conformity (Huston \& Alvarez, 1990; Hill \& Lynch, 1983), perhaps because of physical maturation and the development of secondary sex characteristics and increased opposite-sex interactions. The gender intensification hypothesis posits that the physical changes of puberty are viewed as a signal that the adolescent is transitioning into adulthood and boys and girls experience an intensification of gender-related expectations, which increase their awareness of sex roles 
(Hill \& Lynch, 1983). Moreover, preferential biases for same-sex peers tend to decrease during adolescence when interest in other-sex peers develops (Sippola, Bukowski, \& Noll, 1997; Serbin et al., 1993). Furthermore, puberty elicits secretion of androgenic hormones that are related to sexual arousal in both male and female adolescents (Morris, 1992), which may result in a greater orientation to opposite-sex peers. A shift in preference for oppositesex peers at the time of sexual maturity is also found in nonhuman primates (Sackett, 1970). Thus, sex becomes a salient social category again around the time of puberty.

\section{Amygdala and Sex Biases}

Neuroimaging research has begun to uncover the neural correlates of intergroup attitudes and biases. Implicit affective attitudes are believed to involve subcortical neural structures such as the amygdala, a structure that develops early. The amygdala is involved in detecting salient and motivationally relevant cues in the environment (Cunningham \& Brosch, 2012; Fitzgerald, Angstadt, Jelsone, Nathan, \& Phan, 2006) and is sensitive to social categories (e.g., racial categories; Hart et al., 2000; Phelps et al., 2000). Moreover, the amygdala codes for stimuli that are unusual and interesting (Hamann, Ely, Hoffman, \& Kilts, 2002) as well as novel and unfamiliar (Balderston, Schultz, \& Helmstetter, 2011). Developmentally, amygdala response to race emerges during adolescence (Telzer, Humphreys, Shapiro, \& Tottenham, 2013), a time when racial identity becomes salient (Roberts et al., 1999), suggesting that the amygdala codes for developmentally dependent and motivationally relevant social categories. Thus, the amygdala is a likely candidate to signal to the child the salience of otherness associated with the opposite sex, making it well positioned to detect and process "cooties" in the environment, a neurobiological signal that will facilitate an interest in and future learning about the opposite sex.

Because sex is one of the most salient social categories in early childhood (Martin \& Ruble, 2010), we hypothesized that young children would demonstrate heightened amygdala response to opposite-sex relative to same-sex faces. However, such differential amygdala response would decrease by late childhood, a time when cooties have typically dissipated. Furthermore, we hypothesized that amygdala sensitivity to sex would increase again around puberty, a time when differential sex roles become salient again because of sexual maturation.

\section{METHODS}

\section{Participants}

A total of 117 youth participated. Of these, 93 participated in the behavioral session and 52 participated in the MRI session. Twenty-eight participants completed both sessions.

Behavioral Session-At the behavioral session, 93 youth completed behavioral ratings of their group attitudes toward same- and opposite-sex peers. Participants were evenly split between male $(n=40)$ and female $(n=53)$, ranged in age from 7 to 18 years $\left(M_{\text {age }}=12.0\right.$ years, $S D=2.8$ years) and were ethnically diverse (African American $[n=16]$, Asian American [ $n=22]$, European American [ $n=33]$, Latin American [ $n=10]$, Iranian [ $n=5]$, and other $[n=7])$. Children's IQs were within the normal range $(M=107.2, S D=19.6)$, as

J Cogn Neurosci. Author manuscript; available in PMC 2017 December 10. 
estimated via two subtests from the Wechsler Abbreviated Scale of Intelligence (Wechsler, 1999).

MRI Session-At the MRI session, $52^{1}$ youth completed a functional brain scan. Participants included 28 male participants and 24 female participants, ranged in age from 4 to 18 years ( $M_{\mathrm{age}}=11.0$ years, $S D=3.9$ years), and were ethnically diverse (African American [ $n=14]$, Asian American [ $n=13]$, European American [ $n=16]$, Latin American $[n=7]$, multiracial $[n=1]$, and other [ $n=1])$. Children's IQs were within the normal range $(M=112.3, S D=17.9)$. All participants were physically and psychiatrically healthy, which was confirmed by a telephone screening and psychiatric questionnaire completed by participants' parents (Child Behavior Checklist and related instruments; Achenbach \& Maruish, 1999).

Age Groups-For descriptive purposes, we divided the sample into five developmental age groups. The five groups were defined by dividing the sample into theoretically meaningful age groups with relatively equal numbers of participants in each group. The five age groups included young children (ages 4-6.9 years, $n=15$ ), children (ages 7-10.5 years, $n=32$ ), preteens (ages 10.51-12.5 years, $n=22$ ), mid-teens (ages 12.51-14.5 years, $n=25$ ) and late teens (ages 14.51-18 years, $n=23$ ). The young children did not complete the behavioral session because of difficulties in completing self-reports among this age group. Therefore, behavioral results are presented with four age groups, and the fMRI results are presented with five age groups.

\section{Behavioral Session}

\section{Biases for Same- and Opposite-sex Peers (Group Attitudes Measure)-At}

Session 1, participants completed a group attitudes measure in which they indicated how many girls and boys ( $1=$ none to $5=$ almost all) possessed positive (friendly, smart, honest) and negative attributes (ugly, bad, selfish; Pfeifer et al., 2007). These characteristics are a subset of those used in common trait stereotyping measures (e.g., the Modern Racism Scale (MRS); Doyle \& Aboud, 1995). A positive attitudes measure was calculated by averaging the positive items for each gender, and a negative attitudes measure was calculated by averaging the negative items for each gender. These were coded to reflect same- or oppositesex scores.

Parental Report of Friendships-Parents reported the sex of their child's best friend by indicating whether the friend was the same sex or opposite sex as their child.

Pubertal Status-To examine the role of puberty on neural sensitivity to sex, parents of children 9 years and older completed the Pubertal Development Scale (Petersen, Crockett, Richards, \& Boxer, 1988). Three youth did not have parental reports of pubertal status. Therefore, our sample included 30 youth, ages 9-16. Parents were asked to indicate their child's development in terms of pubic hair, growth spurt, skin changes, facial hair (male only), voice changes (male only), breast development (female only), and age of menarche

\footnotetext{
${ }^{1}$ Note that 32 of these participants were previously reported in a study examining neural sensitivity to African American and European American faces (Telzer et al., 2013).
} 
(female only) on a 4-point scale ranging from not begun to development completed. A mean of all items was calculated, and pubertal status scores could range from 1 to 4 , with higher scores indicating greater pubertal development (pubertal status range $=1-3.6$; mean $=2.4$, $S D=0.9)$. Age and pubertal status were highly correlated $(r=.88, p<.0001)$; therefore, we control for age in all analyses examining puberty.

\section{fMRI Session}

During the fMRI scan, participants completed three functional runs of the Emotional Matching Task, adapted from Hariri et al. (2002). During each run, two blocks of faces were interleaved with two blocks of a sensorimotor control task (shapes). During the faces blocks, participants were presented with a trio of faces and were instructed to make a button response to indicate which of the two faces at the bottom was expressing the same emotion, or felt the same, as the face on top. All stimuli were black-and-white, displayed at $20^{\circ}$, and were expressing one of three emotions: angry, happy, or neutral. The faces were selected from the NimStim Set of Facial Expressions (Tottenham et al., 2009). Half of the faces were female, and half were male. The faces were ethnically diverse, with one-third European American, one-third African American, and one-third Asian American. For the shapes blocks, participants were presented with a trio of shapes and selected one of the two shapes at the bottom that was identical to the shape on top. Each block consisted of six faces or shapes, which were presented for $5 \mathrm{sec}$ each.

fMRI Data Acquisition-Participants were scanned on a Siemens Trio 3.0-T MRI scanner (Erlangen, Germany). A whole-brain, high-resolution, T1*-weighted anatomical scan (MPRAGE; $256 \times 256$ in-plane resolution, $256 \mathrm{~mm}$ field of view; $192 \mathrm{~mm} \times 1 \mathrm{~mm}$ sagittal slices) was acquired for each participant for registration and localization of functional data into Talairach space (Talairach \& Tournoux, 1988). The Emotional Matching Task was presented on a computer screen through MR-compatible goggles. The task was completed during three functional scans, each including $99 \mathrm{~T} 2 *$-weighted echoplanar images (repetition time $=2000 \mathrm{msec}$, echo time $=30 \mathrm{msec}$, flip angle $=90^{\circ}$, matrix size $64 \times 64,34$ slices, 4 $\mathrm{mm}$ voxel, skip $0 \mathrm{~mm}$ ).

fMRI Data Analysis-Functional imaging data were preprocessed and analyzed with the Analysis of Functional NeuroImages (AFNI) software package (Cox, 1996). All data were free of movement greater than $2.5 \mathrm{~mm}$ in any direction. Preprocessing for each participant's images included slice time correction to adjust for temporal differences in slice acquisition within each volume, spatial realignment to correct for head motion, registration to the first volume of each run, spatial smoothing using anisotropic 6-mm Gaussian kernel, FWHM to increase the signal-to-noise ratio, and transformation into the standard coordinate space of Talairach and Tournoux (1988) with parameters obtained from the transformation of each participant's high-resolution anatomical scan. Talairach-transformed images had a resampled resolution of $3 \mathrm{~mm}^{3}$. Time series were normalized to percent signal change to allow comparisons across runs and individuals by dividing signal intensity at each time point by the mean intensity for that voxel and multiplying the result by 100 .

J Cogn Neurosci. Author manuscript; available in PMC 2017 December 10. 
The functional runs were concatenated before creating each participant's individual level model, which included three regressors for each of the stimulus types (male faces, female faces, and shapes) by convolving the stimulus timing files with canonical hemodynamic response function. Six motion parameters were included as separate regressors. General linear modeling was performed to fit the percent signal change time courses to each regressor. Linear and quadratic trends were modeled in each voxel time course to control for correlated drift.

Next, the individual level regression coefficients were submitted to random-effects, grouplevel analyses. We conducted regression analyses using the 3dRegAna program within AFNI to explore how neural responses to same-sex relative to opposite-sex faces changed as a function of age. Age was entered as a regressor in whole-brain regression analyses, controlling for participants' own sex. For female participants, the contrast for the 3dRegAna was male faces > female faces, and for male participants, it was female faces > male faces, therefore representing opposite-sex versus same-sex faces. Analyses examining age-related effects to same-sex and opposite-sex faces separately used the shapes block as the comparison (i.e., same-sex > shapes; opposite-sex > shapes). Exploratory analyses examined age as a curvilinear predictor, in which we entered age and age ${ }^{2}$ as simultaneous regressors. For analyses examining pubertal status, age and puberty were entered in whole-brain regression analyses on the contrast of same-sex > opposite-sex faces, controlling for participants' sex.

Correction for multiple comparisons was applied at the cluster level following Monte Carlo simulations conducted in the $3 \mathrm{dClustSim}$ program within AFNI. This method controls for Type I errors, offering a reasonable correction for multiple tests during group level analyses in ROIs. For our a priori analyses in the amygdala, we used a small-volume corrected threshold (Poldrack et al., 2008). We used an anatomical ROI of the amygdala, which was defined by tracing the anatomical boundaries of the dorsal and ventral amygdala from a T1 template of 27 averaged structural scans. The Monte Carlo simulation indicated a clusterwise threshold at $p<.05$ with nine contiguous voxels in the bilateral amygdala, corresponding to $p<.05$, corrected. At a whole-brain level, the Monte Carlo simulation indicated a cluster-wise threshold at $p<.05$ with 156 contiguous voxels.

\section{RESULTS}

\section{Behavioral Results}

Group Attitudes for Same- and Opposite-sex Peers-Our first analyses examined behavioral attitudes toward same- and opposite-sex peers. We calculated a bias score by subtracting participants' ratings to opposite-sex peers from their ratings for same-sex peers, such that positive scores indicate a bias toward the same sex and negative scores indicate a bias toward the opposite sex. A bias score was calculated for positive attributes and negative attributes. We conducted a repeated-measures ANOVA with Bias scores (positive, negative) to same-sex minus opposite-sex youth as the within-subject factor, Age as a between-subject factor, and Participants' own sex as a covariate. 
We found a significant interaction with Age, such that youths' ratings of positive and negative biases to same-and opposite-sex peers changed with age, $F(3,89)=7.9, p=.006$.

To explore the interaction, we computed paired-samples $t$ tests to examine behavioral biases of same- and opposite-sex youth across the four age groups. As shown in Figure 1A, children showed a significant bias reporting greater positive attributes to their same-sex over opposite-sex and greater negative attributes to the opposite sex over same sex, and preteens showed a marginally significant bias favoring their same sex over opposite sex (children: $t(29)=3.7, p<.001$; preteens: $t(19)=1.8, p=.09)$. Midteens and late teens did not evidence a significant differential bias.

To further explore this age interaction, we examined whether the age-related declines in behavioral biases were being driven by a change in own-sex attitudes, opposite-sex attitudes, or both. In other words, do positive biases to same-sex peers decline with age because youth report the opposite sex to have greater positive attributes with age (i.e., reaching the level of same-sex attitudes) or because youth report the same sex to have fewer positive attributes with age (i.e., reaching the level of opposite-sex attitudes)? We regressed age as a continuous predictor onto youths' positive attitudes for same-sex and opposite-sex peers. Youth reported fewer positive attributes to their own sex as they got older $(\beta=-.36, B=-$. $09, S E=.03, p<.001)$, whereas they did not evidence a developmental change to the opposite sex $(\beta=.05, B=.01, S E=.03, n s)$. Thus, the significant age interaction is driven by a developmental decline in overly positive attitudes toward youths' own sex, such that they reach the level of their opposite-sex attitudes with development (see Figure 1B). For negative attributes, participant ratings increased for both same-sex $(\beta=.52, B=.13, S E=$. $02 p<.001)$ and opposite-sex $(\beta=.22, B=.05, S E=.03 p<.05)$ peers with age, but the effect was twice as large for same-sex peers, such that they reached the level of their opposite-sex attitudes with development (see Figure 1B).

Best Friend's Sex-We compiled the parental ratings of participants' best friends across the two sessions, totaling a sample of 112 youth (five parents did not provide reports). As shown in Table 1, only three parents reported their child to have an opposite-sex best friend. Therefore, an over-whelming bias was found across development, with $97.3 \%$ of youth having a same-sex best friend.

Behavioral Performance on Emotion-matching Task—Next, we examined behavioral performance during the emotion-matching task. In a linear regression with age as the predictor, controlling for participants' sex, youths' accuracy (i.e., percentage of faces matched correctly with emotion) significantly improved with age for opposite-sex faces ( $\beta$ $=.35, p<.05)$ but remained stable across development for same-sex faces $(\beta=.08, n s)$. We calculated the difference between the two dependent correlations (Lee \& Preacher, 2013), which indicates a marginally significant difference $(Z=1.6, p=.05$, one-tailed). As shown in Figure 2, for the youngest participants, accuracy was lower for opposite-sex relative to same-sex faces; with age, this differential performance attenuated. 


\section{fMRI Results}

Neural Sensitivity to Opposite-sex versus Same-sex Faces-In whole-brain regression analyses, we examined neural activation to opposite-sex > same-sex faces, using AFNI's 3dRegAna with age as a regressor of interest and sex as a covariate. We first examined neural activation to the intercept of this contrast, which represents differential neural activation to opposite-sex relative to same-sex faces controlling for participants' age and sex. As shown in Figure 3A, youth showed significantly greater activation to oppositesex relative to same-sex faces in the bilateral dorsal amygdala (see Table 2). There was no main effect for participant sex, suggesting that male and female participants show similar patterns of amygdala activation to opposite-sex relative to same-sex faces. For descriptive purposes, we extracted percent BOLD signal change from the right and left amygdala for opposite-sex faces $>$ shapes and same-sex faces $>$ shapes and plotted the mean estimates for male and female participants. As shown in Figure 3B, both male and female participants showed greater amygdala response to opposite-sex than same-sex faces.

\section{Age-related Changes in Neural Sensitivity to Opposite-sex versus Same-sex}

Faces-Next, we examined how age was associated with neural activation to opposite-sex > same-sex faces, controlling for participants' sex. As shown in Figure 4A, we found a negative correlation in the bilateral amygdala, such that with age, youth showed less activation in the amygdala to opposite-sex relative to same-sex faces (Table 3).

For descriptive purposes, we extracted percent BOLD signal from the significant bilateral amygdala clusters and plotted the mean estimates by age. We divided the sample into five developmental age groups, the same as those used for the behavioral effects, this time with an additional younger group representing young children (ages 4-6). As shown in Figure $4 \mathrm{~B}$, with age, youth showed decreased differentiation of opposite-sex relative to same-sex faces in the bilateral amygdala. Whereas young children and children demonstrated greater amygdala activation to opposite-sex relative to same-sex faces, preteens, teens, and late teens did not evidence differential amygdala activation. To further explore this neural bias to sex as we did in the behavioral analyses, we examined how age related to amygdala activation to same-sex and opposite-sex faces separately. In whole-brain regression analyses, we correlated age onto neural activation to opposite-sex faces > shapes and same-sex faces > shapes. We did not find evidence of age-related increases or decreases in amygdala activation to opposite-sex or same-sex faces, suggesting that the original effect is being driven by the differential response to same- relative to opposite-sex faces rather than to developmental changes to one specific group. To plot this pictorially, we extracted percent BOLD signal change to opposite-sex faces $>$ shapes and same-sex faces $>$ shapes from the amygdala clusters, which showed the significant age-related effect to opposite-sex $>$ samesex faces. As shown in Figure 5C, children showed strong differentiation of same- and opposite-sex faces, but with age, amygdala response to opposite-sex faces declined slightly and amygdala response to same-sex faces increased slightly, such that by the teenage years, youth no longer evidenced differential amygdala response.

J Cogn Neurosci. Author manuscript; available in PMC 2017 December 10. 
For exploratory purposes, we also examined age as a quadratic term to test whether neural responses to same-sex relative to opposite-sex faces changed in a curvilinear pattern across development. We did not find evidence of curvilinear age effects.

Puberty and Neural Sensitivity to Opposite-sex versus Same-sex Faces-Next, we examined how pubertal status relates to neural sensitivity to opposite-sex $>$ same-sex faces within the subsample of youth with pubertal data $(n=30)$. In whole-brain regression analyses, pubertal status and age were entered as continuous regressors with sex as a covariate. As shown in Figure 5, adolescents with more advanced pubertal development compared with their same-aged peers show increased activation to opposite-sex relative to same-sex faces in the bilateral amygdala (right: $t(27)=3.6, p<.05$, corrected, 37 contiguous voxels, $x y z=18-2-10$; left: $t(27)=4.3, p<.05$, corrected, 19 contiguous voxels, $x y z=$ $-16-2-10$ ), extending into the bilateral ventral striatum (right: $x y z=173-5$; left: $x y z=$ -133 -7). In this same subsample, age (controlling for pubertal status) was associated with decreased activation to opposite-sex relative to same-sex faces in the same region of the amygdala $(t(27)=4.2, p<.05$, corrected, 30 contiguous voxels $)$.

\section{Amygdala Response to Sex Mediates Developmental Changes in Behavioral} Biases to Sex-Our final set of analyses examined whether the differential amygdala response to same- and opposite-sex faces mediated the age effect on behavioral biases to sex. This analysis included the 28 youth who participated in both sessions. In a multiple regression analysis, youth evidenced a significant age-related decline in rating positive attributes to same-sex youth (Figure 6). In addition, youth showed a significant age-related decline in differential amygdala response to opposite-sex > same-sex faces. Finally, declines in amygdala response related to lower positive ratings of same-sex peers. Importantly, the total effect was reduced to nonsignificant when amygdala response was entered into the model. The indirect effect is significant, $B=.09, S E=.03, Z=2.8, p<.005$, and the $95 \%$ confidence interval $[.02, .20]$, which was computed using the distribution of products of the coefficients (PRODCLIN; Tofighi \& MacKinnon, 2011), does not include zero, consistent with statistically significant mediation. We did not find significant associations with negative traits or with attitudes to opposite-sex peers. Furthermore, behavioral biases to same- or opposite-sex peers were not correlated with amygdala response to same-sex faces or opposite-sex faces separately. Thus, age-related changes in amygdala response are specific to the differential effect to same- and opposite-sex faces, which is linked to developmental declines in positive ratings to same-sex peers.

\section{DISCUSSION}

Sex is a highly salient social category in early childhood, one that is learned by infancy and by which children rigidly divide the world by age 6 years (Serbin et al., 1994; Trautner, 1992). Young children tend to exaggerate sex boundaries within their play behaviors, intergroup stereotypes, and peer choices (Aydt \& Corsaro, 2003). Our findings replicate behavioral research in human and primate youth (e.g., Mahajan et al., 2011; Alexander \& Hines, 2002; Powlishta, 1995; Serbin et al., 1994; La Freniere et al., 1984), showing that young children evidence strong biases favoring their sex ingroup over outgroup, and such biases wane across development. We demonstrate that these behavioral biases are associated 
with differential amygdala response to same- versus opposite-sex faces, highlighting the amygdala's role in detecting cooties across development.

We found developmental declines in behavioral biases favoring same-sex peers. Only the youngest children in our sample demonstrated a behavioral sex bias such that they rated same-sex peers as having more positive attributes than opposite-sex peers whereas they rated opposite-sex peers as having more negative attributes than same-sex peers. With development, this bias favoring the ingroup dissipated, such that older youth rated same-sex and opposite-sex peers as having equal levels of negative and positive attributes. Our finding of a peak in sex-related stereotypes in early childhood followed by a developmental decline in favoring the ingroup over outgroup is consistent with prior research, showing that rigid sex-related behaviors wane across development (Zosuls et al., 2011; Serbin et al., 1993; Trautner, 1992). We also found that accuracy during the emotion-matching tasks changed across development only for opposite-sex faces, such that accuracy was low early in development and became equal to same-sex performance later in development. Finally, we found a very large preference for same-sex friendships. Taken together, these behavioral measures provide evidence for strong sex-biases evident in young children.

Our behavioral effects were perfectly paralleled by developmental shifts in amygdala sensitivity to sex. Whereas young children demonstrated significantly greater amygdala activation to opposite-sex faces compared to same-sex faces, this effect was completely attenuated by late childhood. Remarkably, children as young as 4 years showed significantly greater amygdala activation to opposite-sex faces compared to same-sex faces, highlighting how early sex-biases develop. Such early development of sex biases may lay the foundation for sustained patterns of sex-typed behaviors. Indeed, we found that $96 \%$ of participants had same-sex best friends, even in adolescence, despite decreased behavioral and neural biases to sex. This is consistent with work showing that preference for same-sex playmates remains strong or even increases across development (Serbin et al., 1993), despite decreases in owngroup favoritism(Egan \& Perry, 2001). Therefore, although behavioral and neural biases to sex may have declined, such early developing biases may impact behavior throughout development via friend choices. Thus, the impact of early sex biases marked by strong ingroup favoritism has potentially long lasting implications, resulting in avoidance of opposite-sex best friends throughout the life span.

Mediation analyses indicated that heightened amygdala response to opposite-sex relative to same-sex faces explained, in part, developmental declines in strong ingroup positivity biases. As the amygdala becomes less sensitive to the opposite sex, ingroup favoritism declines.

Together, these findings suggest that the well-known "cooties effect" may be driven by early developing biases favoring the ingroup coupled with heightened amygdala response to opposite sex faces. Thus, cooties may not only represent negativity toward the opposite sex but also strong ingroup favoritism, which renders the opposite sex more salient and interesting. Indeed, the amygdala codes for stimuli that are both positive and negative, unusual and interesting, and novel and unfamiliar (Balderston et al., 2011; Hamann et al., 2002).

J Cogn Neurosci. Author manuscript; available in PMC 2017 December 10. 
Although we found normative developmental declines in amygdala response to opposite-sex relative to same-sex faces, youth who had more advanced pubertal maturation compared to their same-aged peers evidenced heightened amygdala response to opposite-sex faces. That puberty predicted increase in amygdala response that was independent of age suggests that there is something unique about pubertal maturation that renders opposite-sex faces more salient. It is possible that this occurs through both biological (e.g., sex hormones) and social (e.g., socialization) processes. For instance, theories of gender salience suggest that gender intensification occurs around the time of puberty when physical maturation and the development of secondary sex characteristics intensifies gender-related roles and expectations (Hill \& Lynch, 1983), suggesting a strong role of social processes in increasing the salience of sex differences. In addition, biological processes likely are at play. For instance, the amygdala is densely innervated by gonadal steroid receptors and undergoes significant functional reorganization during puberty (Romeo, Diedrich, \& Sisk, 2000; see Sisk \& Zehr, 2005; Romeo, 2003). Indeed, puberty, and not just age, is associated with enhanced amygdala reactivity to socioemotional stimuli (Moore et al., 2012), consistent with models indicating that puberty involves a social reorientation of the brain (Nelson, Leibenluft, McClure, \& Pine, 2005; Sisk \& Foster, 2004). Thus, opposite-sex faces regain emotional relevance as youth transition into sexual maturity. In addition, the amygdala activation extended into the ventral striatum only at puberty and not in childhood. The ventral striatum codes for salient and rewarding stimuli and has been associated with attractiveness judgments for opposite-sex faces in adults (Cloutier, Heatherton, Whalen, \& Kelley, 2008). Both sex hormones and social influences around the time of puberty increase sexual interest for male and female adolescents (Halpern, Udry, \& Suchindran, 1997; Halpern, Udry, Campbell, \& Suchindran, 1993), which may render opposite-sex faces a more salient and rewarding stimulus. Together, our findings indicate that the amygdala codes for sex during two developmental periods, early childhood and pubertal maturation, are times during which opposite-sex peers are increasingly salient and motivationally relevant social categories.

Altough traditional theories proposed that the amygdala is critical in the detection and processing of threat (Phelps \& LeDoux, 2005), recent research and theory suggests that the amygdala is sensitive to stimuli of any valence that are motivationally relevant and salient, signaling to the organism what is important in the environment and worth paying attention to (Cunningham, Van Bavel, \& Johnsen, 2008; Sander, Grafman, \& Zalla, 2003). Importantly, the amygdala responds to salient social categories, a neural response that is not static but depends on the motivational relevance of the social group and the individuals' current goals and values (Cunningham \& Brosch, 2012; Cunningham et al., 2008). Goals and values will inherently change across development as social categories change in their relative salience, and so the amygdala will code for social categories differentially across development. Indeed, our findings highlight that amygdala sensitivity to social stimuli is modulated by which social category is important during particular developmental stages. The amygdala becomes tuned toward sex during early childhood and puberty, and we previously found that the amygdala becomes tuned toward race during adolescence (Telzer et al., 2013). Sex identity develops relatively early, and sex tends to be a highly salient social category among young children (Martin \& Ruble, 2010; Aydt \& Corsaro, 2003). During adolescence, racial 
identity becomes a more salient social category (Ocampo, Bernal, \& Knight, 1993), and for youth going through puberty, opposite-sex peers regain salience, perhaps because of increasing sexual interest. Together, our findings highlight the role of the amygdala in detecting the developmentally changing salience of these social categories, a neurobiological signal that will facilitate future learning about important social categories.

Sex biases are found across species (Mahajan et al., 2011; Alexander \& Hines, 2002) and tend to increase around the time of puberty when the brain goes through a social reorientation (Nelson et al., 2005; Sisk \& Foster, 2004). In both human, primate, and rodent youth, genetic females exposed to androgenic hormones prenatally show increased preference for male playmates (Hines \& Kaufman, 1994; Berenbaum \& Hines, 1992; Goy, Bercovitch, \& McBrair, 1988; Meaney \& McEwen, 1986), thought to arise because androgen has direct impacts on neural development in relevant brain regions, such as the amygdala (Alexander, 2003). Together, these findings suggest, in part, that there may be innate, biological processes that underlie sex-segregated behaviors and preferences. In addition, although most cultures around the world show relatively strong ingroup sex preferences, suggesting a universality to gender biases, gender identity varies in salience and rigidity across cultures, suggesting that gender segregation is also socialized and constructed through cultural learning (Aydt \& Corsaro, 2003). Therefore, cultural, biological, and social processes likely account for sex-related biases. Future research should attempt to untangle the extent to which developmental changes in amygdala response to opposite-sex faces are accounted for by biological versus socio-cultural influences.

Although our findings suggest that behavioral and neural biases to sex change across development, it is important to acknowledge that all face stimuli were adults. It would be important to replicate our findings with age-matched stimuli. It is possible that the amygdala would respond differentially to similar-aged faces and faces of adults. However, a recent study found that the amygdala is similarly active to adult faces and child faces among youth who are 8-16 years old (Marusak, Carré, \& Thomason, 2013). Moreover, the face stimuli in our study were age incongruent for all participants. Importantly, the amygdala response to opposite-sex faces (even to age-incongruent faces) paralleled the age-related change in appraisals of same- and opposite-sex peers, suggesting that this effect may be independent of the age of the models. Finally, our study relies on a cross-sectional sample of youth.

Although our ages span an impressive range from 4 to 18 years, cross-sectional studies do not provide the ability to examine neural changes. Future studies should use longitudinal methods to examine developmental changes within participants.

In summary, sex-segregated patterns of social interactions are found across species, cultures, and decades of research. Such rigid sex-segregated behaviors and attitudes are therefore normative developmental experiences. Here we provide the first evidence that cooties are mediated by heightened amygdala response to opposite-sex faces relative to same-sex faces. The amygdala therefore plays an integral role in coding for motivationally salient and developmentally specific social categories. 


\section{References}

Achenbach, TM., Maruish, ME., editors. The use of psychological testing for treatment planning and outcomes assessment. 2. Mahwah: Lawrence Erlbaum Associates Publishers; 1999. p. 429-466.

Alexander GM. An evolutionary perspective of sex-typed toy preferences: Pink, blue, and the brain. Archives of Sexual Behavior. 2003; 32:7-14. [PubMed: 12597267]

Alexander GM, Hines M. Sex differences in response to children's toys in nonhuman primates (Cercopithecus aethiops sabaeus). Evolution and Human Behavior. 2002; 23:467-469.

Aydt H, Corsaro WA. Differences in children's construction of gender across culture an interpretive approach. American Behavioral Scientist. 2003; 46:1306-1325.

Balderston NL, Schultz DH, Helmstetter FJ. The human amygdala plays a stimulus specific role in the detection of novelty. Neuroimage. 2011; 55:1889-1898. [PubMed: 21256226]

Berenbaum SA, Hines M. Early androgens are related to childhood sex-typed toy preferences. Psychological Science. 1992; 3:203-206.

Bigler RS, Liben LS. Developmental intergroup theory explaining and reducing children's social stereotyping and prejudice. Current Directions in Psychological Science. 2007; 16:162-166.

Cloutier J, Heatherton TF, Whalen PJ, Kelley WM. Are attractive people rewarding? Sex differences in the neural substrates of facial attractiveness. Journal of Cognitive Neuroscience. 2008; 20:941-951. [PubMed: 18211242]

Cox RW. AFNI: Software for analysis and visualization of functional magnetic resonance neuroimages. Computers and Biomedical Research. 1996; 29:162-173. [PubMed: 8812068]

Cunningham WA, Brosch T. Motivational salience. Amygdala tuning from traits, needs, values, and goals. Current Directions in Psychological Science. 2012; 21:54-59.

Cunningham WA, Van Bavel JJ, Johnsen IR. Affective flexibility: Evaluative processing goals shape amygdala activity. Psychological Science. 2008; 19:152-160. [PubMed: 18271863]

Doyle AB, Aboud FE. A longitudinal study of White children's racial prejudice as a social cognitive development. Merrill Palmer Quarterly. 1995; 41:209-228.

Egan SK, Perry DG. Gender identity: A multidimensional analysis with implications for psychosocial adjustment. Developmental Psychology. 2001; 37:451-463. [PubMed: 11444482]

Fitzgerald DA, Angstadt M, Jelsone LM, Nathan PJ, Phan KL. Beyond threat: Amygdala reactivity across multiple expressions of facial affect. Neuroimage. 2006; 30:1441-1448. [PubMed: 16368249]

Goy RW, Bercovitch FB, McBrair MC. Behavioral masculinization is independent of genital masculinization in prenatally androgenized female rhesus macaques. Hormones and Behavior. 1988; 22:552-571. [PubMed: 3235069]

Halim ML, Ruble DN, Tamis-LeMonda CS. Four-year-olds' beliefs about how others regard males and females. British Journal of Developmental Psychology. 2013; 31:128-135. [PubMed: 23331111]

Halpern CT, Udry JR, Campbell B, Suchindran C. Testosterone and pubertal development as predictors of sexual activity: A panel analysis of adolescent males. Psychosomatic Medicine. 1993; 55:436447. [PubMed: 8265746]

Halpern CT, Udry JR, Suchindran C. Testosterone predicts initiation of coitus in adolescent females. Psychosomatic Medicine. 1997; 59:161-171. [PubMed: 9088053]

Hamann SB, Ely TD, Hoffman JM, Kilts CD. Ecstasy and agony: Activation of the human amygdala in positive and negative emotion. Psychological Science. 2002; 13:135-141. [PubMed: 11933997]

Hariri AR, Mattay VS, Tessitore A, Kolachana B, Fera F, Goldman D, et al. Serotonin transporter genetic variation and the response of the human amygdala. Science. 2002; 297:400-403. [PubMed: 12130784]

Hart AJ, Whalen PJ, Shine LM, McInerney SC, Fischer H, Rauch SL. Differential response in the human amygdala to racial outgroup vs ingroup face stimuli. NeuroReport. 2000; 11:2351-2355. [PubMed: 10943684]

Hill, JP., Lynch, ME. The intensification of gender-related role expectations during early adolescence. In: Brooks-Gunn, J., Petersen, AC., editors. Girls at puberty: Biological and psychosocial perspective. New York: Plenum; 1983. p. 201-228.

J Cogn Neurosci. Author manuscript; available in PMC 2017 December 10. 
Hines M, Kaufman FR. Androgen and the development of human sex-typical behavior: Rough-and tumble play and sex of preferred playmates in children with congenital adrenal hyperplasia (CAH). Child Development. 1994; 65:1042-1053. [PubMed: 7956464]

Huston, AC., Alvarez, MM. The socialization context of gender role development in early adolescence. In: Monte-Mayor, R.Adams, GR., Gullotta, TP., editors. From childhood to adolescence: A transitional period?. Newbury Park, CA: Sage; 1990. p. 156-179.

La Freniere P, Strayer FF, Gauthier R. The emergence of same-sex affiliative preferences among preschool peers: A developmental/ethological perspective. Child Development. 1984; 55:19581965.

Leaper C. Exploring the consequences of gender segregation on social relationships. New Directions for Child and Adolescent Development. 1994; 1994:67-86.

Lee, IA., Preacher, KJ. Calculation for the test of the difference between two dependent correlations with one variable in common. 2013. Available from quantpsy.org

Maccoby, EE., Jacklin, CN. Gender segregation in childhood. In: Reese, HW., editor. Advances in child development and behavior. San Diego, CA: Academic Press; 1987. p. 239-287.

Mahajan N, Martinez MA, Gutierrez NL, Diesendruck G, Banaji MR, Santos LR. The evolution of intergroup bias: Perceptions and attitudes in rhesus macaques. Journal of Personality and Social Psychology. 2011; 100:387. [PubMed: 21280966]

Martin CL, Ruble DN. Patterns of gender development. Annual Review of Psychology. 2010; 61:353.

Martin CL, Ruble D. Children's search for gender cues cognitive perspectives on gender development. Current Directions in Psychological Science. 2004; 13:67-70.

Martin CL, Wood CH, Little JK. The development of gender stereotype components. Child Development. 1990; 61:1891-1904. [PubMed: 2083503]

Marusak HA, Carré JM, Thomason ME. The stimuli drive the response: An fMRI study of youth processing adult or child emotional face stimuli. Neuroimage. 2013; 83:679-689. [PubMed: 23851324]

Meaney MJ, McEwen BS. Testosterone implants into the amygdala during the neonatal period masculinize the social play of juvenile female rats. Brain Research. 1986; 398:324-328. [PubMed: 3801906]

Moore WE, Pfeifer JH, Masten CL, Mazziotta JC, Iacoboni M, Dapretto M. Facing puberty: Associations between pubertal development and neural responses to affective facial displays. Social Cognitive and Affective Neuroscience. 2012; 7:35-43. [PubMed: 22228752]

Morris NM. Determinants of adolescent initiation of coitus. Adolescent Medicine: State of the Art Reviews. 1992; 3:165-180.

Nelson EE, Leibenluft E, McClure E, Pine DS. The social re-orientation of adolescence: A neuroscience perspective on the process and its relation to psychopathology. Psychological Medicine. 2005; 35:163-174. [PubMed: 15841674]

Ocampo, KA., Bernal, ME., Knight, GP. Gender race and ethnicity: The sequencing of social constancies. In: Bernal, ME., Knight, GP., editors. Ethnic identity: Formation and transmission among Hispanic and other minorities. Albany: State University of New York Press; 1993. p. 11-30.

Petersen AC, Crockett L, Richards M, Boxer A. A self-report measure of pubertal status: Reliability, validity, and initial norms. Journal of Youth and Adolescence. 1988; 17:117-133. [PubMed: 24277579]

Pfeifer JH, Ruble DN, Bachman MA, Alvarez JM, Cameron JA, Fuligni AJ. Social identities and intergroup bias in immigrant and nonimmigrant children. Developmental Psychology. 2007; 43:496. [PubMed: 17352555]

Phelps EA, LeDoux JE. Contributions of the amygdala to emotion processing: From animal models to human behavior. Neuron. 2005; 48:175-187. [PubMed: 16242399]

Phelps EA, O'Connor KJ, Cunningham WA, Funayma ES, Gatenby JC, Gore JC, et al. Performance on indirect measures of race evaluation predicts amygdala activity. Journal of Cognitive Neuroscience. 2000; 12:1-10.

Poldrack RA, Fletcher PC, Henson RN, Worsley KJ, Brett M, Nichols TE. Guidelines for reporting an fMRI study. Neuroimage. 2008; 40:409-414. [PubMed: 18191585]

Powlishta KK. Gender bias in children's perceptions of personality traits. Sex Roles. 1995; 32:17-28. 
Powlishta, KK. Gender as a social category: Intergroup processes and gender-role development. In: Bennet, M., Sano, F., editors. The development of the social self. New York: Psychology Press; 2004. p. 103-134.

Roberts RE, Phinney JS, Masse LC, Chen R, Roberts CR, Romero A. The structure of ethnic identity of young adolescents from diverse etnocultural groups. The Journal of Early Adolescence. 1999; 19:301-322.

Romeo RD. Puberty: A period of both organizational and activational effects of steroid hormones on neurobehavioural development. Journal of Neuroendocrinology. 2003; 15:1185-1192. [PubMed: 14636181]

Romeo RD, Diedrich SL, Sisk CL. Effects of gonadal steroids during pubertal development on androgen and estrogen receptor-a immunoreactivity in the hypothalamus and amygdala. Journal of Neurobiology. 2000; 44:361-368. [PubMed: 10942888]

Sackett, GP. Unlearned responses, differential rearing experiences, and the development of social attachments by rhesus monkeys. In: Rosemblum, LA., editor. Primate behavior: Developments in field and laboratory research. New York: Academic Press; 1970. p. 111-140.

Samuelson S. The cooties complex. Western Folklore. 1980; 39:198-210.

Sander D, Grafman J, Zalla T. The human amygdala: An evolved system for relevance detection. Reviews in the Neurosciences. 2003; 14:303-316. [PubMed: 14640318]

Serbin LA, Moller LC, Gulko J, Powlishta KK, Colburne KA. The emergence of sex segregation in toddler playgroups. New Directions in Child Development. 1994; 65:7-17.

Serbin LA, Powlishta KK, Gulko J. The development of sex typing in middle childhood. Monographs of the Society for Research in Child Development. 1993; 58:1-95.

Signorella ML, Bigler RS, Liben LS. Developmental differences in children's gender schemata about others: A meta-analytic review. Developmental Review. 1993; 13:147-183.

Sippola LK, Bukowski WM, Noll RB. Dimensions of liking and disliking underlying the same-sex preference in childhood and early adolescence. Merrill-Palmer Quarterly. 1997; 43:591-609.

Sisk CL, Foster DL. The neural basis of puberty and adolescence. Nature Neuroscience. 2004; 7:10401047. [PubMed: 15452575]

Sisk CL, Zehr JL. Pubertal hormones organize the adolescent brain and behavior. Frontiers in Neuroendocrinology. 2005; 26:163-174. [PubMed: 16309736]

Sroufe IA, Bennett C, Englund M, Urban J, Shulman S. The significance of gender boundaries in adolescence: Contemporary correlates and antecedents of boundary violation and maintenance. Child Development. 1993; 64:455-466. [PubMed: 8477628]

Talairach J, Tournoux P. Co-planar stereotaxic atlas of human brain. 3-Dimensional proportional system: An approach to cerebral imaging. 1988

Telzer EH, Humphreys K, Shapiro M, Tottenham NL. Amygdala sensitivity to race is not present in childhood but emerges in adolescence. Journal of Cognitive Neuroscience. 2013; 25:234-244. [PubMed: 23066731]

Tofighi D, MacKinnon DP. RMediation: An R package for mediation analysis confidence intervals. Behavior Research Methods. 2011; 43:692-700. [PubMed: 21487904]

Tottenham N, Tanaka JW, Leon AC, McCarry T, Nurse M, Hare TA, et al. The NimStim set of facial expressions: Judgments from untrained research participants. Psychiatry Research. 2009; 168:242249. [PubMed: 19564050]

Trautner HM. The development of sex-typing in children: A longitudinal analysis. German Journal of Psychology. 1992; 16:183-199.

Trautner HM, Ruble DN, Cyphers L, Kirsten B, Behrendt R, Hartmann P. Rigidity and flexibility of gender stereotypes in childhood: Developmental or differential? Infant and Child Development. 2005; 14:365-381.

Wechsler, D. The Wechsler Abbreviated Scale of Intelligence. New York: The Psychological Corporation; 1999.

Yee M, Brown R. The development of gender differences in young children. British Journal of Social Psychology. 1994; 33:183-196. [PubMed: 8044502] 
Zosuls KM, Martin CL, Ruble DN, Miller CF, Gaertner BM, England DE, et al. It's not that we hate you: Understanding children's gender attitudes and expectancies about peer relationships. British Journal of Developmental Psychology. 2011; 29:288-304. [PubMed: 21592150] 


\section{A}
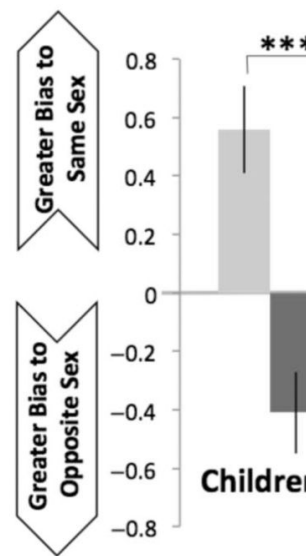

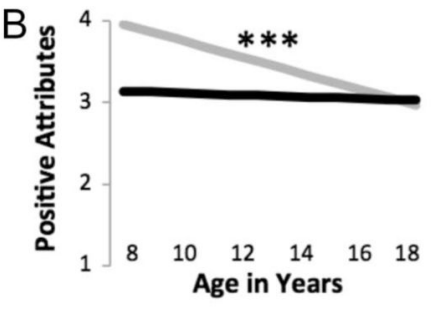

- same-sex peers - opposite-sex peers

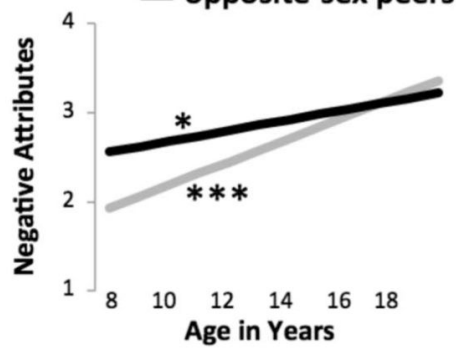

Figure 1.

(A) Children demonstrate a bias such that they report their own sex to have greater positive attributes and the opposite sex to have greater negative attributes. This bias becomes marginally significant in preteens and disappears for midteens and late teens. (B) Children's ratings for positive attributes to same-sex peers declines significantly, and their ratings for negative attributes to same-sex peers increases significantly, such that youths' same-sex attitudes reach the level of their opposite-sex attitudes with development. $* * * p<.001, * p<$. $05,{ }^{+} p<.10$. Error bars represent the SEM. 


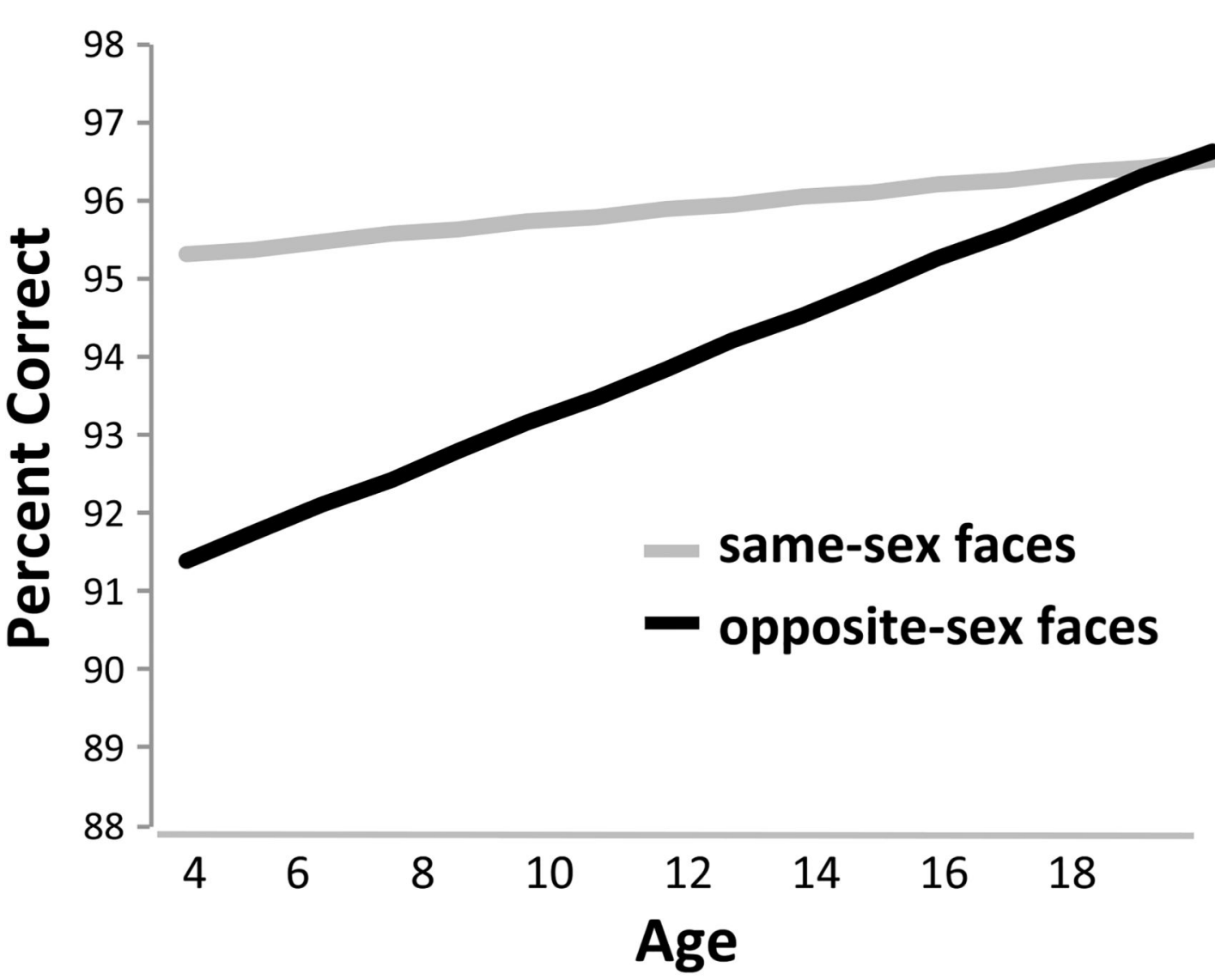

Figure 2.

Behavioral performance on the emotion-matching task. With age, participants show improved accuracy for identifying the emotional expression of opposite-sex faces. Accuracy for same-sex faces remains high across development. 


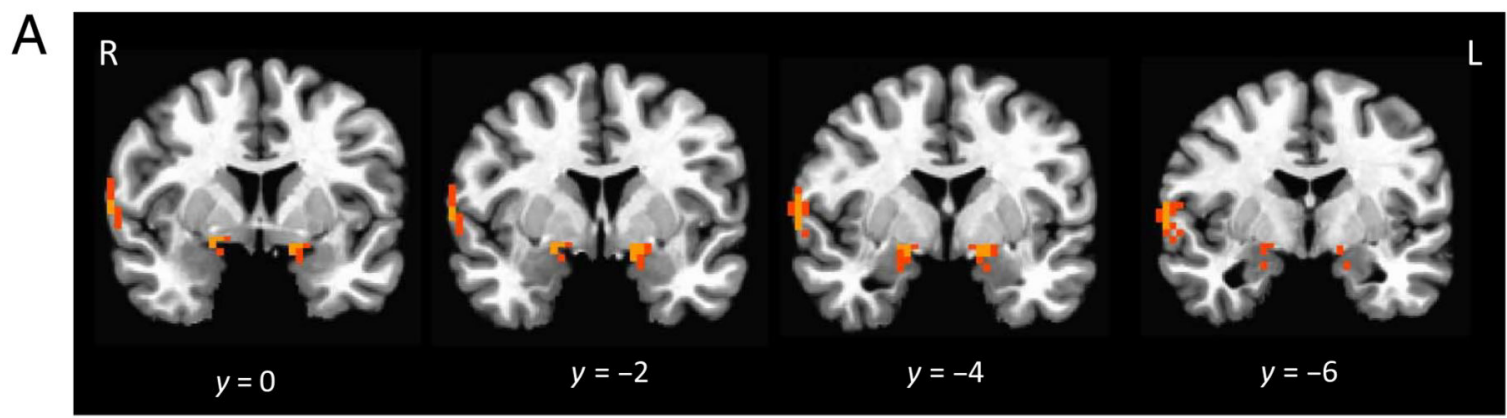

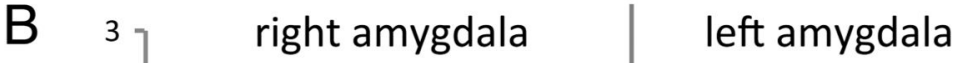

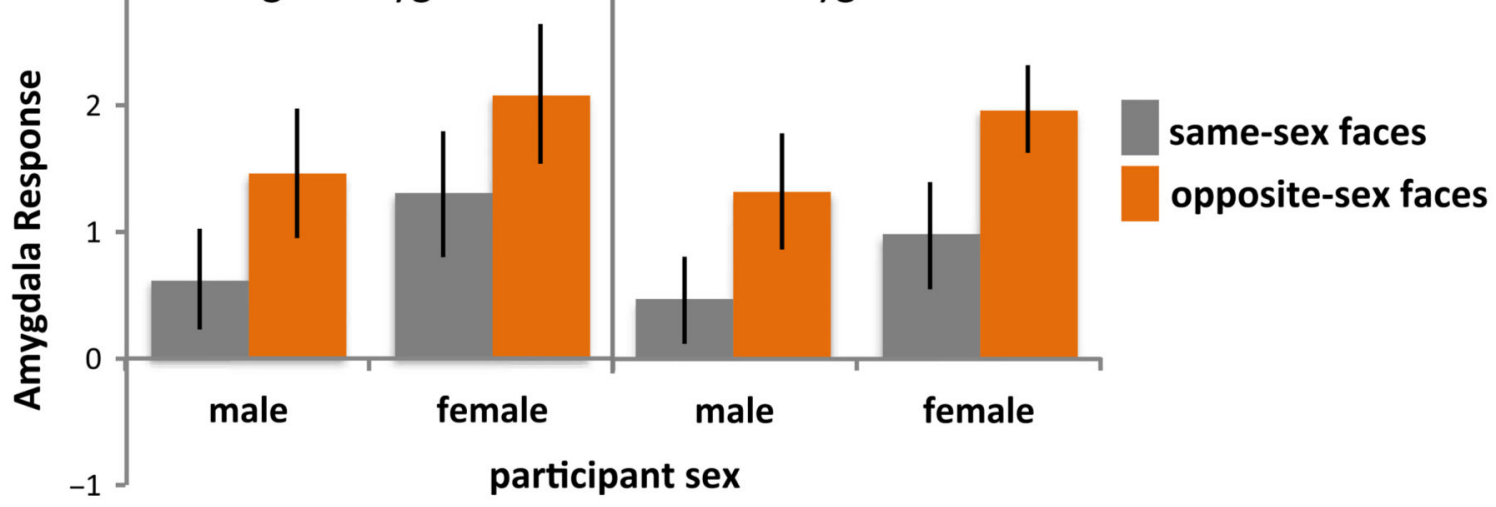

(A) Main effect of amygdala response to opposite-sex > same-sex faces, controlling for age and sex. (B) For descriptive purposes only, we divided the sample by participant sex and extracted percent BOLD signal response from the right and left amygdala for opposite-sex and same-sex faces. Error bars represent the SEM. 


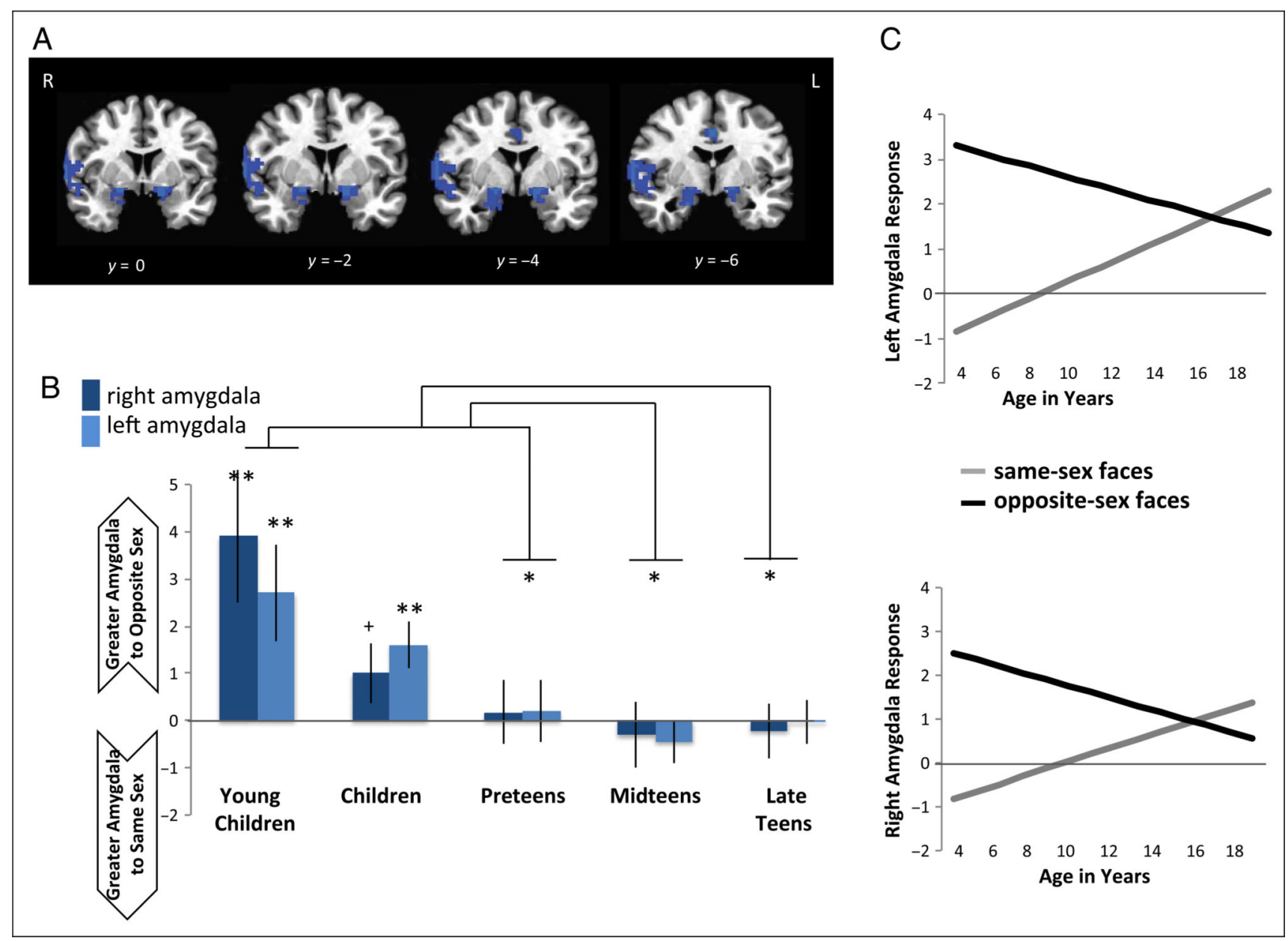

Figure 4.

(A) Correlating age on neural activation to opposite-sex $>$ same-sex faces. Age is a continuous variable. (B) For descriptive purposes, we divided the sample into five age groups and plotted amygdala response to opposite-sex > same-sex faces. With age, youth show decreased differentiation to opposite-sex versus same-sex faces in the bilateral amygdala. Young children and children evidenced significantly greater amygdala activation to opposite-sex than same-sex faces, whereas preteens, midteens, and late teens did not show differential amygdala response. Significance levels, represented by symbols directly above the bars, represent post hoc, one-sample $t$ tests indicating amygdala response significantly different than 0 . In addition, post hoc, two-sample $t$ tests comparing each age group show that young children evidenced significantly greater differential amygdala response than preteens, midteens, and late teens. Significance levels are represented by lines showing differences between age groups. (C) Age-related changes in amygdala response to same-sex and opposite-sex faces. ${ }^{* *} p<.01,{ }^{*} p<.05,{ }^{+} p<.10$. Error bars represent the SEM. 

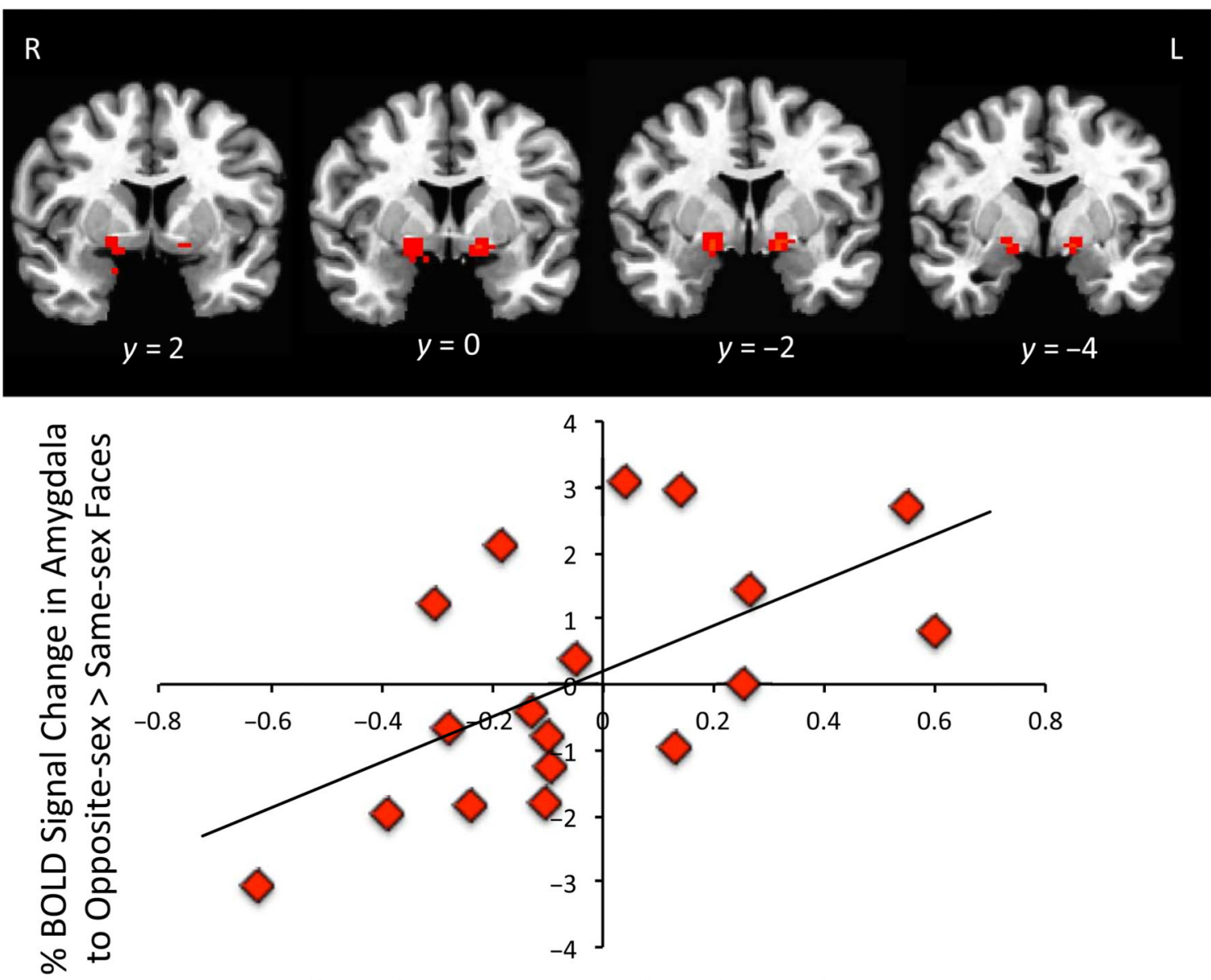

Pubertal Status (controlling for age)

Figure 5.

Controlling for age, higher pubertal status is associated with increased activation to opposite-sex faces relative to same-faces in the bilateral amygdala $(n=30)$. 


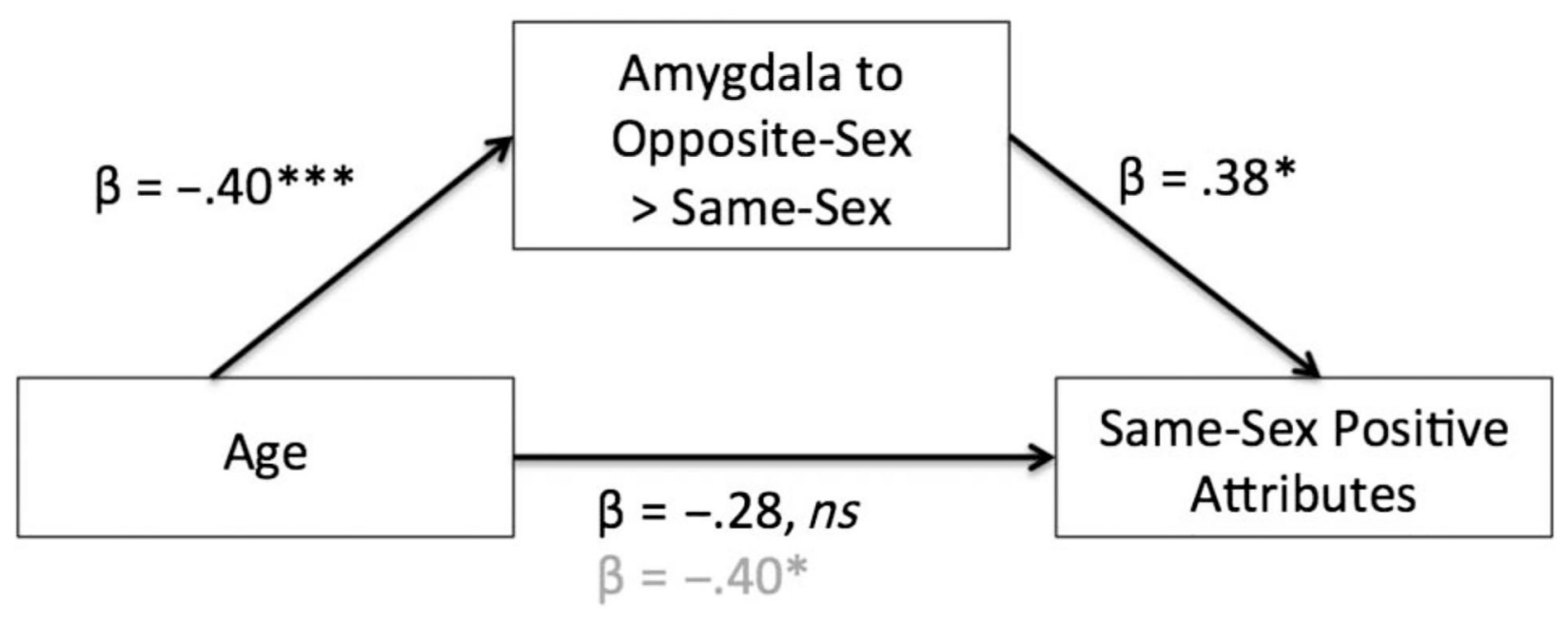

Figure 6.

Amygdala response to opposite sex > same sex faces mediates developmental changes in behavioral biases favoring same-sex peers. 


\section{Table 1}

Number of Same-sex and Opposite-sex Best Friends Reported by Parents of Young Children, Children, Preteens, Midteens, and Late Teens

\begin{tabular}{lrc}
\hline & Same Sex & Opposite Sex \\
\cline { 2 - 3 } & \multicolumn{2}{c}{$\mathbf{n}$} \\
\hline Young children & 15 & 0 \\
Children & 30 & 1 \\
Preteens & 18 & 2 \\
Midteens & 24 & 0 \\
Late teens & 22 & 0 \\
Total & 109 & 3 \\
\hline
\end{tabular}



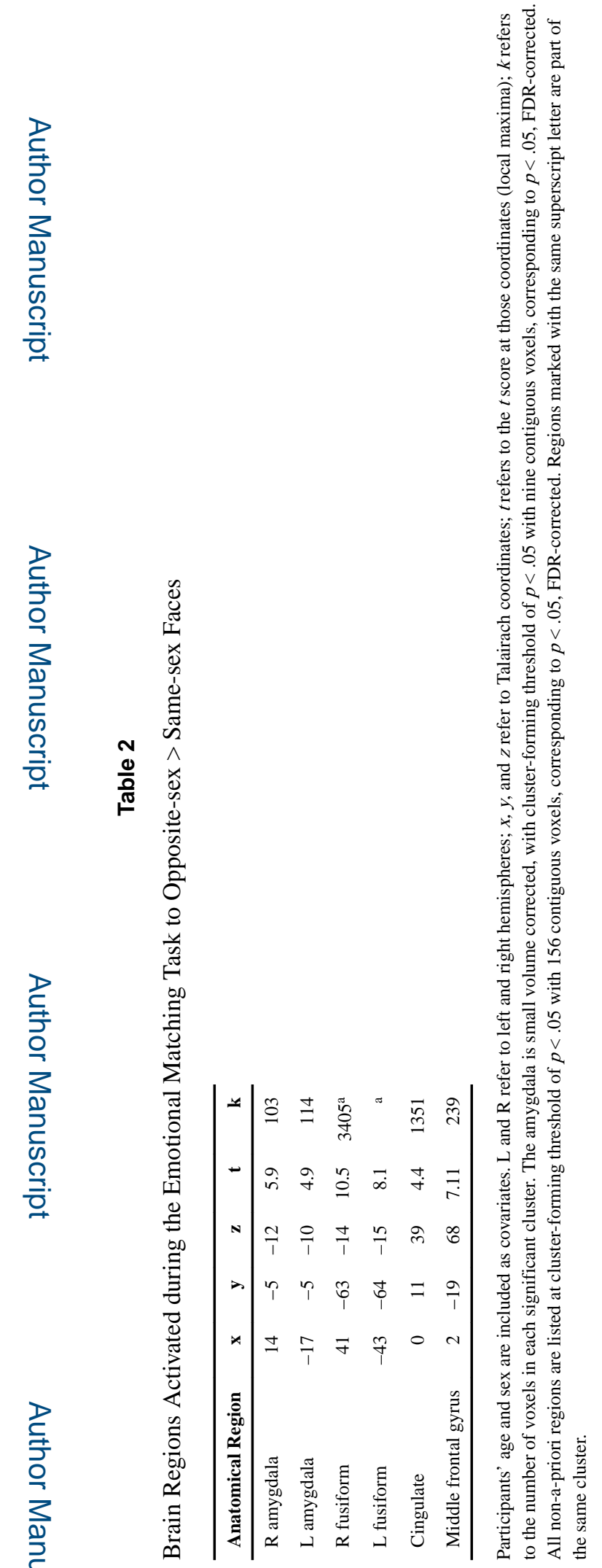

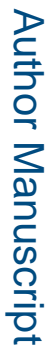

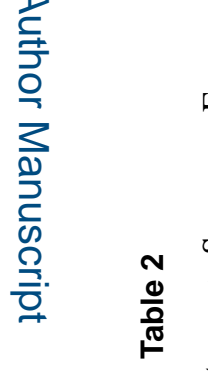

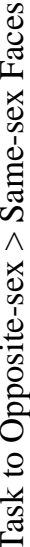

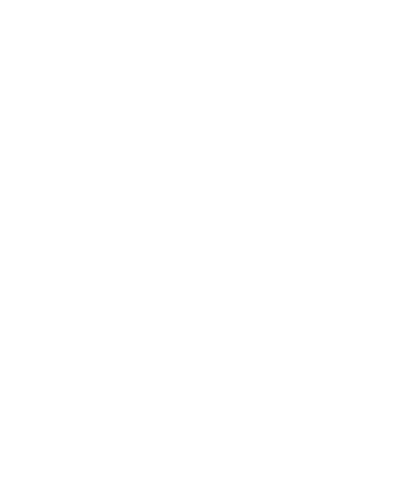

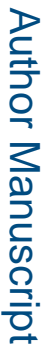

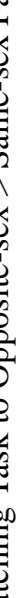

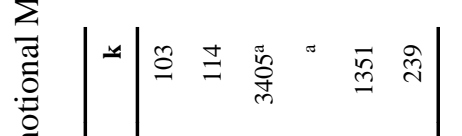

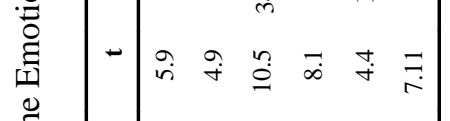

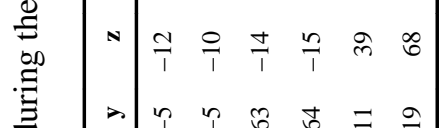

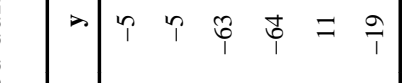

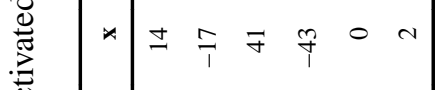

究 


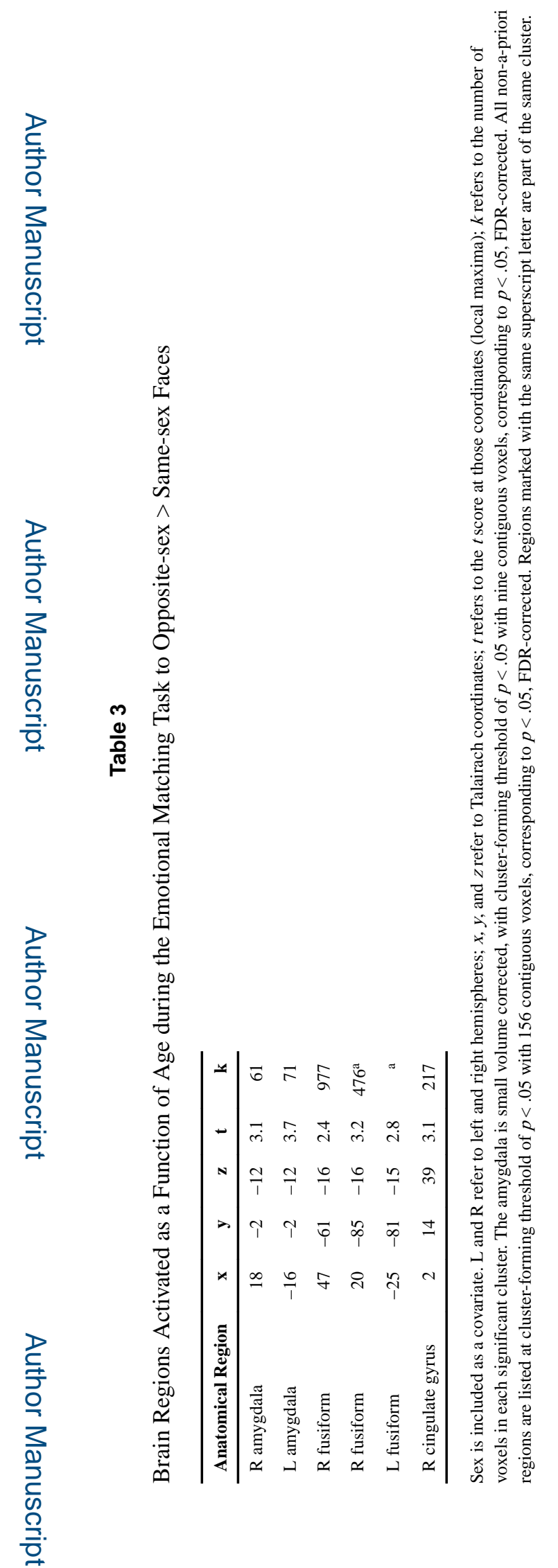

J Cogn Neurosci. Author manuscript; available in PMC 2017 December 10. 